\title{
Distal pronator teres motor branch transfer for wrist extension restoration in radial nerve paralysis
}

\author{
Jayme Augusto Bertelli, MD, PhD, ${ }^{1,2}$ Sushil Nehete, MD, ${ }^{3}$ Elisa Cristiana Winkelmann Duarte, $\mathrm{PhD},{ }^{4}$ \\ Neehar Patel, MD, ${ }^{5}$ and Marcos Flávio Ghizoni, MD, MSc ${ }^{1}$ \\ ${ }^{1}$ Department of Neurosurgery, Center of Biological and Health Sciences, University of the South of Santa Catarina (Unisul), \\ Tubarão; ${ }^{2}$ Department of Orthopedic Surgery, Governador Celso Ramos Hospital, Florianópolis, Santa Catarina, Brazil; \\ ${ }^{3}$ Department of Plastic Surgery, Wockhardt Hospital, Mumbai, Maharashtra, India; ${ }^{4}$ Department of Anatomy, Federal University \\ of Santa Catarina, Florianópolis, Santa Catarina, Brazil; and ${ }^{5}$ Bombay Hospital Institute of Medical Sciences, New Marine Lines, \\ Mumbai, Maharashtra, India
}

OBJECTIVE The authors describe the anatomy of the motor branches of the pronator teres (PT) as it relates to transferring the nerve of the extensor carpi radialis brevis (ECRB) to restore wrist extension in patients with radial nerve paralysis. They describe their anatomical cadaveric findings and report the results of their nerve transfer technique in several patients followed for at least 24 months postoperatively.

METHODS The authors dissected both upper limbs of 16 fresh cadavers. In 6 patients undergoing nerve surgery on the elbow, they dissected the branches of the median nerve and confirmed their identity by electrical stimulation. Of these 6 patients, 5 had had a radial nerve injury lasting 7-12 months, underwent transfer of the distal PT motor branch to the ECRB, and were followed for at least 24 months.

RESULTS The PT was innervated by two branches: a proximal branch, arising at a distance between 0 and $40 \mathrm{~mm}$ distal to the medial epicondyle, responsible for PT superficial head innervation, and a distal motor branch, emerging from the anterior side of the median nerve at a distance between 25 and $60 \mathrm{~mm}$ distal to the medial epicondyle. The distal motor branch of the PT traveled approximately $30 \mathrm{~mm}$ along the anterior side of the median nerve; just before the median nerve passed between the PT heads, it bifurcated to innervate the deep head and distal part of the superficial head of the PT. In $30 \%$ of the cadaver limbs, the proximal and distal PT branches converged into a single trunk distal to the medial epicondyle, while they converged into a single branch proximal to it in $70 \%$ of the limbs. The proximal and distal motor branches of the PT and the nerve to the ECRB had an average of 646, 599, and 457 myelinated fibers, respectively.

All patients recovered full range of wrist flexion-extension, grade M4 strength on the British Medical Research Council scale. Grasp strength recovery achieved almost $50 \%$ of the strength of the contralateral side. All patients could maintain their wrist in extension while performing grasp measurements.

CONCLUSIONS The distal PT motor branch is suitable for reinnervation of the ECRB in radial nerve paralysis, for as long as 7-12 months postinjury.

https://thejns.org/doi/abs/10.3171/2019.10.JNS192110

KEYWORDS radial nerve repair; nerve grafting; radial nerve paralysis; nerve transfer; posterior interosseous nerve; tendon transfer; peripheral nerve

$\mathrm{C}$ LOSED humeral fracture is the most common cause of radial nerve paralysis in adults.? Indications for nerve repair are based on the absence of functional and electrophysiological recovery by the 3rd to 4th month postinjury. ${ }^{11}$ However, spontaneous recovery, which occurs in $70 \%$ of patients, can start as late as 7 months after the accident. ${ }^{27,29}$ Given that only spontaneous recovery can provide restoration of normal function, interventions on the radial nerve, such as nerve grafting or nerve transfers, should be evaluated very carefully. On the other hand, delays of more than 5 months can result in poor outcomes with nerve grafting. ${ }^{25}$ This being said, the case is not the same for distal nerve transfers, which can provide adequate results for wrist extension restoration even 10-18

ABBREVIATIONS BMRC = British Medical Research Council; DPT = distal PT; ECRB = extensor carpi radialis brevis; FCR = flexor carpi radialis; PIN = posterior interosseous nerve; $\mathrm{PPT}=$ proximal $\mathrm{PT} ; \mathrm{PT}=$ pronator teres.

SUBMITTED August 7, 2019. ACCEPTED October 29, 2019.

INCLUDE WHEN CITING Published online January 17, 2020; DOI: 10.3171/2019.10.JNS192110. 

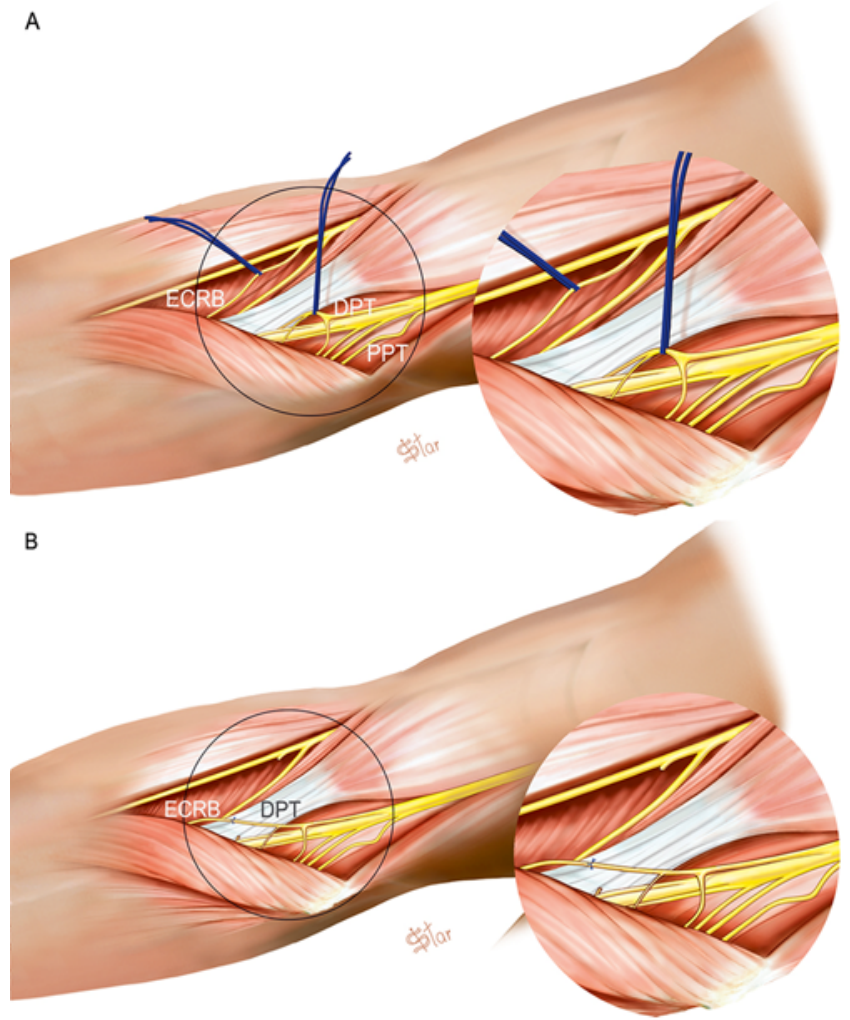

FIG. 1. A and B: Schematic representations of the surgical technique. Copyright Jayme Augusto Bertelli. Published with permission. Figure is available in color online only.

months after injury. ${ }^{3,11}$ We believe that 6 months without signs of recovery is the minimal delay before surgical intervention. Considering this long wait-and-see interval, we have increased the use of distal nerve transfers in our practice for radial nerve repair.

For radial nerve paralysis, wrist extension restoration is crucial. ${ }^{20} \mathrm{~A}$ few donors for nerve transfer to treat wrist extension paralysis have been described. Ray and Mackinnon ${ }^{26}$ connected motor branches of the flexor digitorum superficialis to the motor branch of the extensor carpi radialis brevis (ECRB). García-López et al..$^{13}$ transferred a branch of the pronator teres (PT) to the extensor carpi radialis longus motor branch, while Bertelli et al. ${ }^{4}$ transferred the distal anterior interosseous nerve to the ECRB motor branch. In the majority of cases, two motor branches innervate the PT. ${ }^{18}$ These branches have been indistinctly used as donors for radial ${ }^{13,23}$ and lower-type injuries of the brachial plexus ${ }^{17,38}$ or as recipients after median nerve injury. ${ }^{36}$ Even though some anatomical studies pertaining to nerve transfer surgery for radial nerve restoration have been published, $, 85,37$ the course and disposition of the PT branches and histomorphometric analysis are lacking. We propose transferring the most distal motor branch of the PT to the ECRB for restoration of wrist extension for radial nerve paralysis. We report here our anatomical and histomorphometric findings and clinical results.

\section{Methods}

In advance of any data collection, the local ethics committee of the University of the South of Santa Catarina (Unisul) approved the protocol of the present study. Patients provided written informed consent prior to their participation. Our primary goal was to describe the anatomy of the PT motor branches as a means to use the distal branch (distal PT [DPT]) as a donor for transfer to the ECRB motor branch. Our secondary goal was to evaluate the effectiveness of transferring the DPT motor branch to the ECRB motor branch in terms of restoring wrist extension in cases of radial nerve paralysis (Fig. 1). For the clinical study, we used purposeful sampling, which included patients whose radial nerve lesions were a minimum of 6 and a maximum of 12 months old, operated on between January 2016 and May 2017 by the senior author (J.A.B.) (Table 1).

\section{Anatomical Studies}

We studied both forearms of 16 fresh cadavers. We dissected the median nerve at the antecubital fossa and its branches to the PT. We identified the origin of the motor branches of the PT in relation to the medial epicondyle. We counted the number of motor branches and observed to which head of the PT they provided innervation. For each motor branch, we documented its site of origin on the median nerve. Using a ruler, we measured the following: the distance of the motor branch origin on the median nerve to the medial epicondyle; the branch length from its origin to the muscle entrance; and the branch diameter.

TABLE 1. Summary of data in patients with radial nerve injury

\begin{tabular}{|c|c|c|c|c|c|c|c|c|c|}
\hline \multirow{2}{*}{$\begin{array}{l}\text { Patient } \\
\text { No. }\end{array}$} & \multirow{2}{*}{$\begin{array}{l}\text { Age (yrs), } \\
\text { Sex, Side }\end{array}$} & \multirow[b]{2}{*}{ Cause } & \multirow{2}{*}{$\begin{array}{l}\text { Nerve } \\
\text { Injury }\end{array}$} & \multirow{2}{*}{$\begin{array}{l}\text { Preop-Postop } \\
\text { Interval (mos) }\end{array}$} & \multirow[b]{2}{*}{ Wrist ROM } & \multicolumn{3}{|c|}{ Grasping Strength } & \multirow{2}{*}{$\begin{array}{l}\text { Wrist Flexion in Max } \\
\text { Grasping Strength }\end{array}$} \\
\hline & & & & & & Pre & Post & Normal & \\
\hline 1 & $23, \mathrm{~F}, \mathrm{rt}$ & Humeral fracture & Radial & $9-24$ & Complete & 4.5 & 8 & 16 & No \\
\hline 2 & $27, \mathrm{M}, \mathrm{rt}$ & Humeral fracture & Radial & $12-24$ & Complete & 6 & 18 & 40 & No \\
\hline 3 & $48, \mathrm{M}$, It & Humeral fracture & Radial & $7-29$ & Complete & 4 & 21 & 41 & No \\
\hline 4 & $23, \mathrm{~F}, \mathrm{rt}$ & Humeral fracture & Radial & $7-24$ & Complete & 2 & 10 & 20 & No \\
\hline 5 & $31, \mathrm{M}$, It & Infraclavicular gunshot & Radial & $7-24$ & Complete & 7 & 13 & 35 & No \\
\hline 6 & $25, \mathrm{M}, \mathrm{rt}$ & Humeral fracture & Radial & 7 & $?$ & 3 & & & $?$ \\
\hline
\end{tabular}

$\mathrm{ROM}=$ range of motion; ? = not known, patient lost to follow-up. 
We dissected the PT muscle, including both its superficial and deep heads, and investigated the relationships of the two heads to the median nerve and adjacent structures.

Samples of the proximal and distal branches of the PT, together with samples of the ECRB motor branch, were removed, fixed in $70 \%$ alcohol, embedded in a paraffin section, transversely sectioned, and stained with $\mathrm{H} \& \mathrm{E}$. Photographs were taken under a microscope, and myelinated fibers were counted manually. All dissections were videotaped.

\section{Patients}

Two sets of patients were involved in our study. In the first set of patients, we were interested in studying the anatomy of the branches of the median nerve after dissection and electrical stimulation. This group included 18 patients with radial nerve or posterior cord paralysis $(n=9)$, brachial plexus paralysis $(n=3)$, tetraplegia $(n=4)$, and anterior elbow release $(n=2)$. The second set of patients-those who had a radial nerve injury $(n=6)$-then underwent transfer of the DPT motor branch to the nerve to the ECRB for wrist extension restoration, and the motor branch of the FCR to the posterior interosseous nerve (PIN) for finger and thumb extension restoration; they were followed for at least 24 months. All patients with a humeral fracture were victims of high-energy trauma following a motorcycle accident. All underwent open reduction and internal fixation of the humeral fracture. In all, radial nerve paralysis was observed before surgical plating. All patients had at least one electrodiagnostic test around 6 months postoperatively indicating a lack of nerve recovery. Details of the study population are summarized in Table 1.

\section{Surgery}

Patients were operated on while supine under general anesthesia without muscle relaxants. Surgery was performed via an oblique incision on the antecubital fossa. After skin and subcutaneous division, we divided the lacertus fibrosus to expose the median nerve. We located the proximal and distal branches of the PT, together with the anterior interosseous nerve and FCR motor branches. We dissected the radial nerve and individualized the PIN and the ECRB motor branch. We then sectioned the DPT and sutured it to the ECRB. The nerve to the FCR was divided and transferred to the PIN to restore thumb and finger extension (Fig. 1 and Video 1).

VIDEO 1. Intraoperative view of transferring the DPT motor branch to the nerve to the ECRB for wrist extension restoration, and the motor branch of the FCR to the PIN for thumb and finger extension restoration in a patient with radial nerve paralysis. Copyright Jayme Augusto Bertelli. Published with permission. Click here to view.

\section{Postoperative Care and Evaluation}

After surgery, patients' treated arms were maintained in a soft dressing for 10 days. Patients received no specific physiotherapy training but were encouraged to use the affected hand in daily activities.

Patients were followed up regularly and had a final evaluation at a minimum of 24 months after surgery. For the evaluation of wrist extension restoration, we mea-

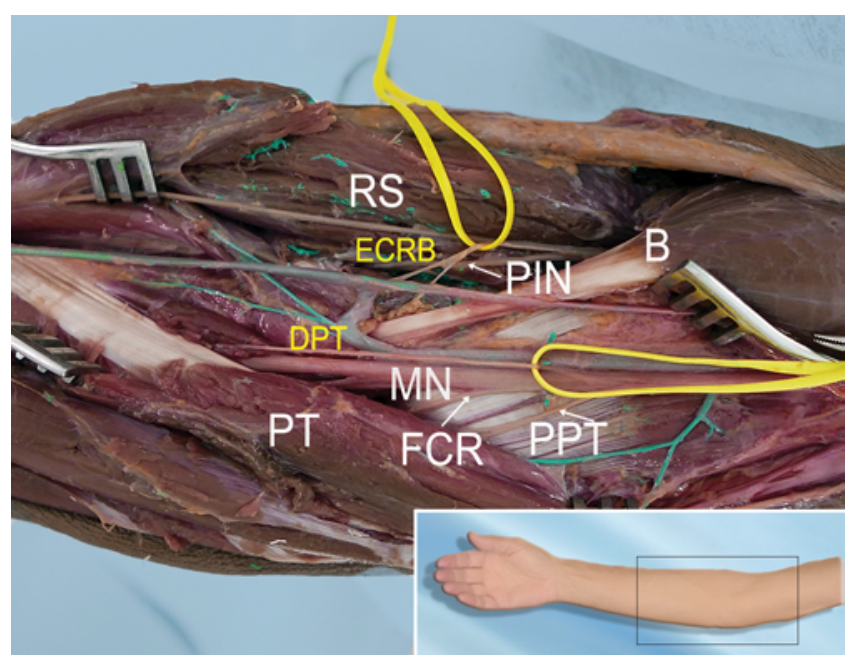

FIG. 2. Anatomical dissection of the right antecubital fossa in a cadaver intraarterially injected with green latex. Note the biceps tendon (B), the proximal branch of the PT, the motor branch of the FCR, the radial superficial nerve (RS), the PIN, and the median nerve (MN). The ECRB and the DPT motor branch are tagged by yellow vessel loops. Inset shows the area on the arm where the dissection takes place. Figure is available in color online only.

sured the range of wrist extension using the Goniometer Pro iPhone app. If active range of motion was the same as passive range of motion, we deemed that range of motion was complete. We scored the recovery of wrist extension strength using the British Medical Research Council (BMRC) scale. Preoperatively and postoperatively, we measured grasp strength with a Jamar dynamometer (Baseline Hydraulic Hand Dynamometer; Fabrication Enterprises Inc.) with the patient's hand set in position 2. For this, the forearm was at $30^{\circ}$ of supination while the wrist was in self-selected degrees of extension. Patients were instructed to pressure the dynamometer maximally while the examiner verbally encouraged them. The maximum grasp strength was recorded when, under the forces of finger flexion, the wrist flexed. The recorded value was the maximum one obtained after a set of 3 measurements.

\section{Statistical Analysis}

All values are reported as means (SD). Intergroup differences were considered statistically significant when $p<$ 0.05 . After surgery, the magnitude of grasp strength improvement was evaluated by calculating Cohen's d value, where $0.2-0.39$ indicated a small effect, $0.4-0.79$ a moderate effect, and $\geq 0.8$ a large effect. ${ }^{21}$

\section{Results}

\section{Anatomical Findings \\ Cadavers}

The PT was innervated by two main motor branches arising independently from the median nerve distal to the medial epicondyle in 23 specimens of the 32 dissections (Fig. 2). There was one proximal (proximal PT [PPT]) and one distal (DPT) branch. The PPT originated from 


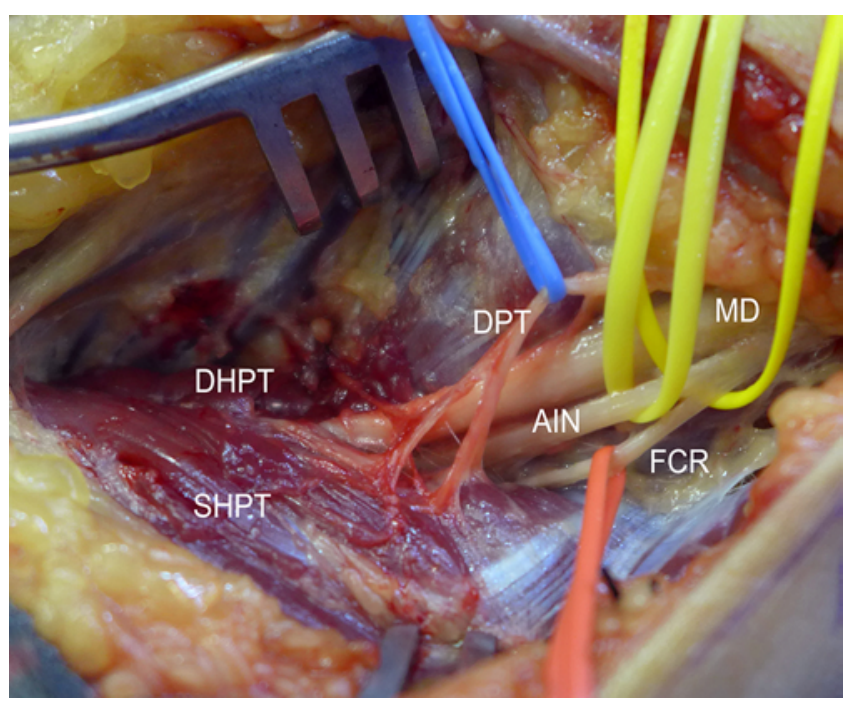

FIG. 3. Intraoperative view of the termination of the DPT motor branch into the superficial (SHPT) and deep (DHPT) heads of the PT, median nerve (MD), anterior interosseous nerve (AIN), and FCR motor branch. Figure is available in color online only.

the anterior or medial surface of the median nerve at the medial epicondyle $(n=4)$ or distally to it $(n=22)$ at a mean distance of $15 \mathrm{~mm}$ (SD $14 \mathrm{~mm}$; range 0-40 $\mathrm{mm}$ ). Its mean diameter was $1.4 \mathrm{~mm}$ (SD $0.4 \mathrm{~mm}$; range $0.9-2$ $\mathrm{mm}$ ), and its mean length was $27 \mathrm{~mm}$ (SD $8 \mathrm{~mm}$; range $16-43 \mathrm{~mm}$ ). The trajectory of the PPT motor branch was obliquely downward to innervate the superficial head of the PT. The PPT motor branch had an average of 646 myelinated fibers (SD 249 myelinated fibers; range 326-1224 myelinated fibers). In 2 dissections, we noted the FCR motor branch arising from the PPT branch.

The DPT motor branch arose from the anterior surface of the median nerve, running downward along the top of the median nerve for 30-40 mm (Fig. 2). Its origin was, on average, $38 \mathrm{~mm}$ (SD $11 \mathrm{~mm}$; range 25-60 mm) distal to the medial epicondyle. Just before the median nerve pierced the PT, the DPT motor branch trifurcated, sending two branches to the superficial head and one to the deep head of the PT (Fig. 3). In cases in which the DPT's termination was bifurcated, there was one branch to the superficial and one to the deep head of the PT. The branch's mean diameter was $1.3 \mathrm{~mm}$ (SD $0.4 \mathrm{~mm}$; range $0.9-2 \mathrm{~mm}$ ), and its mean length was $38 \mathrm{~mm}$ (SD $15 \mathrm{~mm}$; range 20-75 mm). In 4 specimens, the FCR motor branch stemmed from the DPT. In 1 specimen, a flexor digitorum superficialis branch arose from the DPT. The DPT had, on average, 599 myelinated fibers (SD 150 myelinated fibers; range 320-778 myelinated fibers), whereas the ECRB averaged 457 myelinated fibers (SD 174 myelinated fibers; range 218-835 myelinated fibers). Histomorphometric data are summarized in Table 2.

When the DPT and PPT branches were neurolized proximally, we observed convergence of these branches to form a single trunk, $40-55 \mathrm{~mm}$ proximal to the medial epicondyle (Fig. 4). In 7 dissections, this convergence occurred $0-40 \mathrm{~mm}$ distal to the medial epicondyle. This was the case where a single branch stemmed from the median nerve distal to the medial epicondyle. However, this single branch always divided into a proximal and distal branch in such a way that in no dissection was there a single point of innervation of the PT (Video 2).

VIDEO 2. Cadaveric dissection of the PT motor branch. Copyright Jayme Augusto Bertelli. Published with permission. Click here to view.

In no case was the median nerve superficial to the PT. In all our dissections, the median nerve passed between the two heads of the PT, if both heads were present. We observed the absence of the deep head of the PT in 1 case and hypoplasia in 5 other dissections.

\section{Patients}

In 15 of the 18 patients, we recognized both a proximal and a distal branch to the PT. In 2 patients, we observed one trunk that, after a short trajectory, sent a proximal branch to the PT and continued as the DPT motor branch (Fig. 5). In 1 patient with tetraplegia, we could not find the PPT branch.

\section{Clinical Outcomes}

One of the 6 patients in whom there was a radial nerve injury was lost to follow-up. The remaining 5 patients recovered active wrist extension against resistance, with complete range of motion that was grade M4 on the BMRC scale. Postoperatively, we observed a marked increase in grasp strength (Cohen's d of 2.5). In all cases, we observed that patients could maintain their wrist in an extended position associated with maximum grasp strength. Grasp strength recovery was roughly $50 \%$ of the strength seen on the normal side (Table 1). Pronation strength was preserved in all patients.

\section{Discussion}

In $70 \%$ of our 54 dissections, we identified two motor branches to the PT, similar to previous reports. ${ }^{8,15,18}$ When proximally dissected above the elbow, these two branch-

TABLE 2. Histomorphometric data for the PT motor branches

\begin{tabular}{ccccc}
\hline Motor Branch & $\begin{array}{c}\text { Distance From the Origin to the } \\
\text { Medial Epicondyle, } \mathrm{mm}\end{array}$ & Length, mm & Diameter, mm & No. of Myelinated Fibers \\
\hline PPT & $14(0-40)$ & $27(16-43)$ & $1.4(0.9-2)$ & $646(326-1224)$ \\
\hline DPT & $38(25-60)$ & $38(20-75)$ & $1.3(0.9-2)$ & $599(360-778)$ \\
\hline \multicolumn{4}{l}{ Values are presented as the mean (range of variation). }
\end{tabular}




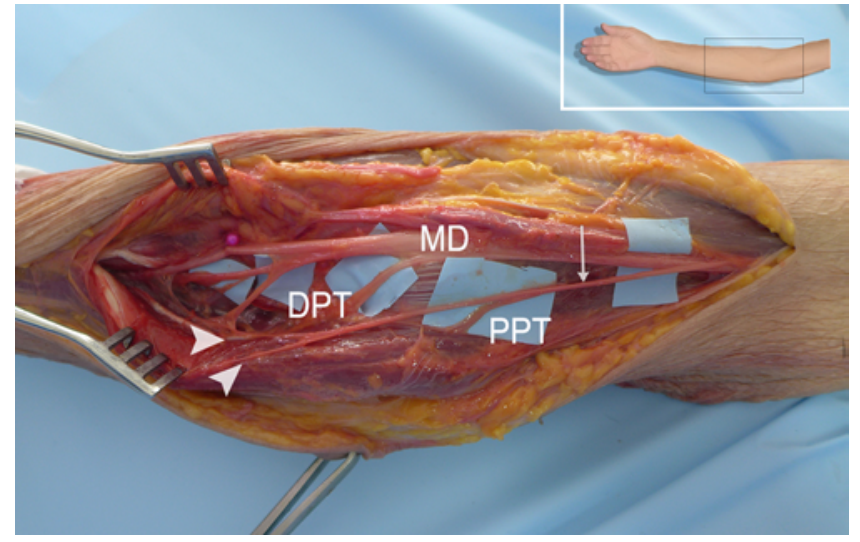

FIG. 4. Fresh cadaver dissection of the right antecubital fossa showing the DPT and PPT motor branches. Arrowheads indicate the termination of the DPT motor branch into the superficial and deep heads of the PT. When proximally dissected, both PT branches converged into a single anterior trunk (arrow). This conversion occurred in 7 of our 32 specimens below the elbow. Internal neurolysis could transform a double branch into a single trunk. MD = median nerve. Figure is available in color online only.

es converged into a single trunk, in agreement with the findings of Gunther et al. ${ }^{14}$ In contrast, Chantelot et al. ${ }^{10}$ and Basanagouda and Halagatti ${ }^{1}$ identified only a single branch to the PT in more than $65 \%$ of their dissections. We believe that variations between our findings and those of others ${ }^{1,10,15}$ - concerning the number, length, and origin of nerve branches-were a direct result of the anatomical dissection itself. Most of the other studies used embalmed cadavers, which are difficult to dissect. ${ }^{1,6,10,15,35} \mathrm{We}$ used fresh cadavers and in vivo dissection, followed by electrical stimulation, which we believe is more precise. Gunther et al..$^{14}$ observed that gross dissection findings of PT branches were different than those of their own extended microdissections. What is important, however, is that at least one proximal and one distal motor entry point existed regularly in the PT, ${ }^{19,38}$ allowing one branch to be harvested for transfer without complete PT denervation.

The PPT is the first branch of the median nerve at the elbow. It arises from the medial or posterior side of the median nerve, is short, and has a downward trajectory to enter the superficial head of the PT. Several investigators share this description of the PT's proximal or superior branch. ${ }^{14,32}$ In contrast, the description of the DPT motor branch is varied and imprecise. ${ }^{34}$ It has been reported as originating from the posterior surface of the median nerve within a common trunk to the muscle of the superficial layer of the forearm..$^{24,34}$ This is in contrast with our findings. We regularly identified the DPT motor branch arising independently from the anterior or medial side of the median nerve, traveling on its anterior surface and bifurcating to the superficial and deep heads of the PT, just before crossing it.

We observed the absence of the deep head of the PT in 1 among our 32 cadaveric dissections. Caetano et al. ${ }^{9}$ observed the lack of the deep PT head in 14 of 100 dissections, while Jamieson and Anson ${ }^{16}$ noted its absence
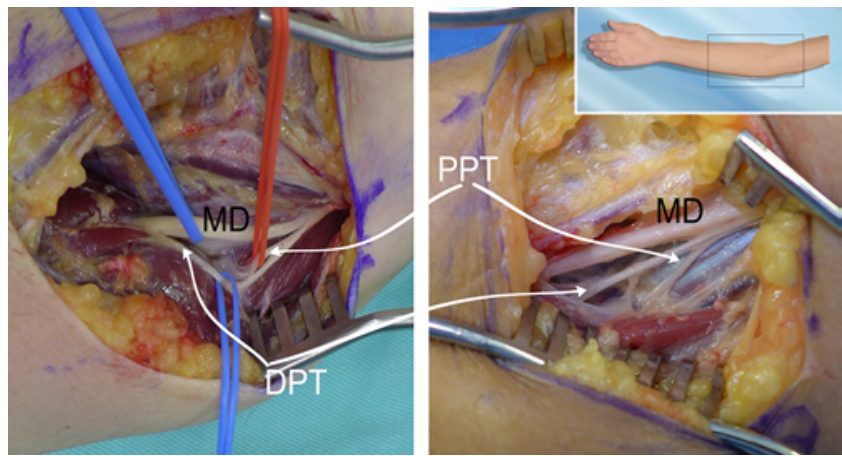

FIG. 5. Intraoperative photographs of 2 cases in which a single nerve stemmed from the median nerve (MD) below the elbow. Note that, in both dissections, a PPT and DPT can be individualized. Division of the DPT at its entrance into the PT preserves the PPT motor branch. Figure is available in color online only.

in 26 of 300 observations. When both PT heads were present, the median nerve passed between them in all our observations, as well as in the dissections of Caetano et al. ${ }^{9}$ Conversely, Jamieson and Anson ${ }^{16}$ noted the median nerve passing under the two heads of the PT in 18 cases and piercing the superficial head in 6 cases among 300 dissections. Of importance, as with ours, Caetano et al.'s ${ }^{9}$ and Jamieson and Anson's ${ }^{16}$ findings included the median nerve never running superficial to the PT. Caetano et al. ${ }^{9}$ observed hypoplasia of the deep head of the PT in 21 of 100 dissections, while we observed it in 5 of 32 cadaveric dissections. In this situation, we observed that a single branch at the origin of the median nerve distal to the elbow joint innervated the PT; however, it entered the PT at different points.

In our study, the number of myelinated fibers in the proximal and distal PT motor branch was similar. In contrast, Tung and Mackinnon ${ }^{36}$ found an average of 476 fibers versus 933 for the proximal and distal PT branches, respectively. Sukegawa et al. ${ }^{31}$ reported an average of 548 myelinated fibers in the ECRB motor branch, while we counted an average of 457. From our results, we conclude that both PT branches can be used to reinnervate the ECRB motor branch, with no difference in the average number of myelinated fibers. However, our preference is to use the DPT motor branch because it is closer to our targets, and it is longer after neurolysis, which facilitates surgery. It is important intraoperatively, however, to identify branches of the FCR that can arise from the DPT. In cases in which only a single branch to the PT emerges from the median nerve, harvesting remains possible. This single branch always provides a motor branch to the proximal portion of the PT. Nerve sectioning for transfer should be distal to this first branch.

We consider our nerve transfer successful in 4 ways: 1 ) it restored full active range of motion in wrist extension; 2) wrist extension was grade M4 on the BMRC scale for manual muscle testing; 3 ) it improved grasp strength; and 4) it preserved wrist extension during maximal grasp strength measurement. Measurements of grasp strength are influenced by wrist extension strength. ${ }^{30,33}$ During 
grasping, if recovered wrist extension strength is weak, the strong finger flexor will drive the wrist into flexion and power is lost. Regarding the BMRC scale, our outcomes compare favorably with previous reports..$^{4,13,26}$ That being said, grasp strength is difficult to compare with previous studies, because these other authors have failed to indicate the wrist position at which grasp strength was measured and if, during measurement, the wrist flexed. In all our patients, we observed a baseline value of grasp strength different from grade 0 . This probably reflects the capacity of using gravity, following some degrees of supination, to balance dynamometer position, thereby inhibiting immediate wrist flexion while beginning to press on the dynamometer. If grasp strength was measured in wrist flexion, the antagonistic strength of wrist extensors would be missed. In a wrist-flexed position, grasp strength reached an average of $40 \%$ of normal, ${ }^{5}$ which would be a confounding factor in our evaluation of successful nerve transfers. After surgery, all our patients could have their maximal grasp strength recorded without concomitant wrist flexion. In our series, we observed no failures of wrist extension recovery. Even patients operated on 12 months after their injury had good results, comparable to those of patients operated on earlier. Our 3 patients who underwent surgery 7 months postinjury recovered an average of $46 \%$ of their grasp strength relative to the normal hand, whereas those operated on later achieved $45 \%$. All of our patients underwent a preoperative electrophysiological evaluation that indicated a lack of nerve recovery. However, we believe that electrophysiological studies are of limited value as a screening mechanism for spontaneous recovery. For instance, Bumbasirević et al. ${ }^{7}$ observed that, after surgical exploration, 8 of 14 patients with radial nerve paralysis who exhibited no electromyography evidence of recovery 4 months after injury ultimately progressed to exhibit a full recovery despite the absence of nerve repair. Conversely, Dolan and Giele ${ }^{12}$ reported 2 patients with nerve interruption in whom preoperative neurophysiological studies indicated nerve continuity. One must also bear in mind that early electrophysiological signs of muscle reinnervation do not necessarily correlate with ultimate full clinical recovery. ${ }^{28}$ Other than radiographical control for fracture healing, no imaging studies were requested for our patients to evaluate radial nerve continuity, mostly because of the long delay between the injury and when the patient presented. High-resolution ultrasonography could be of use in identifying radial nerve transection. However, radial nerve transection following a humeral fracture is quite rare. Yörükoğlu et al. ${ }^{39}$ discovered radial nerve transection in only 1 among 24 patients with radial nerve paralysis following a humeral fracture. We recommend waiting at least 6 months before undertaking a nerve transfer. We operated on our patients later because of their late presentation. We even consider nerve transfers 12 months postinjury. We have abandoned radial nerve grafting as the sole treatment in cases of high-energy trauma with humeral fracture or with lesions proximal to the humerus. In both situations, the results of grafting have been disappointing. ${ }^{2,22,27}$

The limitations of our study are related to the small number of patients we operated on and the patients being evaluated by the same surgeon who performed the surgery.
Although some bias could exist, we believe that it is more than compensated for by the large effect size we observed when comparing the pre- and postoperative evaluations.

\section{Conclusions}

We believe that the DPT is useful for transfer for wrist extension restoration in radial nerve paralysis, having an adequate number of myelinated fibers available to reinnervate the ECRB. Our results also suggest that nerve transfers for wrist extension restoration are useful for longstanding paralysis up to 12 months.

\section{Acknowledgments}

We are indebted to Dr. Lilian Brillinger Novello, director of the IML/IGP-Florianópolis, who made this research possible. We would like to express our gratitude to the staff of the IML/IGP for their help with our anatomical project.

\section{References}

1. Basanagouda $\mathrm{C}$, Halagatti M: Innervation pattern of pronator teres muscle and its relation to median nerve: a cadaveric study. Int J Anat Res 5:4092-4095, 2017

2. Bertelli JA, Ghizoni MF: Results of nerve grafting in radial nerve injuries occurring proximal to the humerus, including those within the posterior cord. J Neurosurg 124:179-185, 2016

3. Bertelli JA, Ghizoni MF, Tacca CP: Results of wrist extension reconstruction in C5-8 brachial plexus palsy by transferring the pronator quadratus motor branch to the extensor carpi radialis brevis muscle. J Neurosurg 124:1442-1449, 2016

4. Bertelli JA, Tacca CP, Winkelmann Duarte EC, Ghizoni MF, Duarte H: Transfer of the pronator quadratus motor branch for wrist extension reconstruction in brachial plexus palsy. Plast Reconstr Surg 130:1269-1278, 2012

5. Bhardwaj P, Nayak SS, Kiswar AM, Sabapathy SR: Effect of static wrist position on grip strength. Indian J Plast Surg 44:55-58, 2011

6. Bindurani M, Lokessh H, Nanjundappa N: Study of muscular branch of median nerve to the pronator teres. Nat J Clin Anat 2:67-70, 2017

7. Bumbasirević M, Lesić A, Bumbasirević V, Cobeljić G, Milosević I, Atkinson HDE: The management of humeral shaft fractures with associated radial nerve palsy: a review of 117 cases. Arch Orthop Trauma Surg 130:519-522, 2010

8. Caetano EB, Vieira LA, Sabongi Neto JJ, Caetano MBF, Sabongi RG, Martinez L, et al: Anatomical study of pronator teres muscle innervation and clinical significance in nerve transfer. Int J Morphol 36:1500-1508, 2018

9. Caetano EB, Vieira LÂ, Sprovieri FAA, Petta GC, Nakasone MT, Serafim BLC: Anatomical variations of pronator teres muscle: predispositional role for nerve entrapment. Rev Bras Ortop 52:169-175, 2017

10. Chantelot C, Feugas C, Guillem P, Chapnikoff D, Rémy F, Fontaine C: Innervation of the medial epicondylar muscles: an anatomic study in 50 cases. Surg Radiol Anat 21:165168,1999

11. Davidge KM, Yee A, Kahn LC, Mackinnon SE: Median to radial nerve transfers for restoration of wrist, finger, and thumb extension. J Hand Surg Am 38:1812-1827, 2013

12. Dolan RT, Giele HP: Radial nerve palsies associated with paediatric supracondylar humeral fractures: a caution in the interpretation of neurophysiological studies. J Pediatr Orthop B [epub ahead of print], 2019

13. García-López A, Navarro R, Martinez F, Rojas A: Nerve 
transfers from branches to the flexor carpi radialis and pronator teres to reconstruct the radial nerve. J Hand Surg Am 39:50-56, 2014

14. Gunther SF, DiPasquale D, Martin R: The internal anatomy of the median nerve in the region of the elbow. J Hand Surg Am 17:648-656, 1992

15. Gupta C, Seva KN, Kalthur SG, D'souza AS: A morphometric study of variations in the innervation of pronator teres with its clinical implications. J Med Sci 35:97-93, 2015

16. Jamieson RW, Anson BJ: The relation of the median nerve to the heads of origin of the pronator teres muscle, a study of 300 specimens. Q Bull Northwest Univ Med Sch 26:34-35, 1952

17. Li Z, Reynolds M, Satteson E, Nazir O, Petit J, Smith BP: Double distal intraneural fascicular nerve transfers for lower brachial plexus injuries. J Hand Surg Am 41:e15-e19, 2016

18. Linell EA: The distribution of nerves in the upper limb, with reference to variabilities and their clinical significance. J Anat 55:79-112, 1921

19. Liu J, Pho RW, Pereira BP, Lau HK, Kumar VP: Distribution of primary motor nerve branches and terminal nerve entry points to the forearm muscles. Anat Rec 248:456-463, 1997

20. Ljungquist KL, Martineau P, Allan C: Radial nerve injuries. J Hand Surg Am 40:166-172, 2015

21. Page P: Beyond statistical significance: clinical interpretation of rehabilitation research literature. Int J Sports Phys Ther 9:726-736, 2014

22. Pan $\mathrm{CH}$, Chuang DC, Rodríguez-Lorenzo A: Outcomes of nerve reconstruction for radial nerve injuries based on the level of injury in 244 operative cases. J Hand Surg Eur 35:385-391, 2010

23. Plate JF, Ely LK, Pulley BR, Smith BP, Li Z: Combined proximal nerve graft and distal nerve transfer for a posterior cord brachial plexus injury. J Neurosurg 118:155-159, 2013

24. Poirier P, Charpy A, Cunéo B: Abrégé d'anatomie. Paris: Masson et Cie, 1908, p 997

25. Pollock FH, Drake D, Bovill EG, Day L, Trafton PG: Treatment of radial neuropathy associated with fractures of the humerus. J Bone Joint Surg Am 63:239-243, 1981

26. Ray WZ, Mackinnon SE: Clinical outcomes following median to radial nerve transfers. J Hand Surg Am 36:201-208, 2011

27. Ring D, Chin K, Jupiter JB: Radial nerve palsy associated with high-energy humeral shaft fractures. J Hand Surg Am 29:144-147, 2004

28. Şahin F, Atalay NŞ, Akkaya N, Ercidoğan Ö, Başakçi B, Kuran B: The correlation of neurophysiological findings with clinical and functional status in patients following traumatic nerve injury. J Hand Surg Eur 39:199-206, 2014

29. Shao YC, Harwood P, Grotz MRW, Limb D, Giannoudis PV: Radial nerve palsy associated with fractures of the shaft of the humerus: a systematic review. J Bone Joint Surg Br 87:1647-1652, 2005

30. Souza VK, Claudino AF, Kuriki HU, Marcolino AM, Fonseca MCR, Barbosa RI: Fatigue of the wrist extensor muscles decreases palmar grip strength. Fisioter Pesqui 24:100-106, 2017
31. Sukegawa K, Suzuki T, Ogawa Y, Kobayashi T, Matsuura Y, Kuniyoshi K: A cadaver study of median-to-radial nerve transfer for radial nerve injuries. J Hand Surg Am 41:20 26,2016

32. Sunderland S, Ray LJ: Metrical and non-metrical features of the muscular branches of the median nerve. J Comp Neurol 85:191-203, 1946

33. Suzuki T, Kunishi T, Kakizaki J, Iwakura N, Takahashi J, Kuniyoshi K: Wrist extension strength required for power grip: a study using a radial nerve block model. J Hand Surg Eur Vol 37:432-435, 2012

34. Testut I, Latarjet A: Tratado de Anatomia Humana, ed 9. Barcelona: Salvat, 1983, pp 276-277

35. Tubbs RS, Beckman JM, Loukas M, Shoja MM, CohenGadol AA: Median nerve branches to the pronator teres: cadaveric study with potential use in neurotization procedures to the radial nerve at the elbow. J Neurosurg 114:253-255, 2011

36. Tung THH, Mackinnon SE: Flexor digitorum superficialis nerve transfer to restore pronation: two case reports and anatomic study. J Hand Surg Am 26:1065-1072, 2001

37. Ustün ME, Ogün TC, Büyükmumcu M: Neurotization as an alternative for restoring finger and wrist extension. J Neurosurg 94:795-798, 2001

38. Yang J, Jia X, Yu C, Gu Y: Pronator teres branch transfer to the anterior interosseous nerve for treating C8T1 brachial plexus avulsion: an anatomic study and case report. Neurosurgery 75:375-379, 2014

39. Yörükoğlu AC, Demirkan AF, Büker N, Akman A, Ok N: Humeral shaft fractures and radial nerve palsy: early exploration findings. Eklem Hastalik Cerrahisi 27:41-45, 2016

\section{Disclosures}

The authors report no conflict of interest concerning the materials or methods used in this study or the findings specified in this paper.

\section{Author Contributions}

Conception and design: Bertelli. Acquisition of data: all authors. Analysis and interpretation of data: Bertelli. Drafting the article: Bertelli, Patel. Critically revising the article: Bertelli, Nehete, Ghizoni. Reviewed submitted version of manuscript: Bertelli. Approved the final version of the manuscript on behalf of all authors: Bertelli. Statistical analysis: Bertelli.

\section{Supplemental Information \\ Videos}

Video 1. https://vimeo.com/372359234.

Video 2. https://vimeo.com/372359271.

\section{Correspondence}

Jayme Augusto Bertelli: Governador Celso Ramos Hospital, Florianópolis, SC, Brazil. drbertelli@gmail.com. 